\title{
MIDAS
}

Museus e estudos interdisciplinares

$8 \mid 2017$

Dossier temático "Objetos e museus: biografias, narrativas e vínculos identitários"

\section{Inês Ferreira - Criatividade nos Museus: Espaços "Entre" e Elementos de Mediação}

\section{Francisco Providência}

\section{(2) OpenEdition}

\section{Journals}

Edição electrónica

URL: http://journals.openedition.org/midas/1166

DOI: 10.4000/midas. 1166

ISSN: 2182-9543

\section{Editora:}

Alice Semedo, Paulo Simões Rodrigues, Pedro Casaleiro, Raquel Henriques da Silva, Ana Carvalho

\section{Refêrencia eletrónica}

Francisco Providência, «Inês Ferreira - Criatividade nos Museus: Espaços "Entre" e Elementos de Mediação », MIDAS [Online], 8 | 2017, posto online no dia 31 julho 2017, consultado no dia 24 setembro 2020. URL : http://journals.openedition.org/midas/1166; DOI : https://doi.org/10.4000/midas.1166

Este documento foi criado de forma automática no dia 24 setembro 2020.

\section{cc) (ஒ)}

Midas is licensed under a Creative Commons Attribution-NonCommercial-ShareAlike 3.0 International License 


\title{
Inês Ferreira - Criatividade nos
}

\section{Museus: Espaços "Entre" e Elementos de Mediação}

\author{
Francisco Providência
}

\section{REFERÊNCIA}

Ferreira, Inês. 2016. Criatividade nos Museus: Espaços "Entre" e Elementos de Mediação. Vol. 3. Coleção Estudos de Museu. Casal de Cambra: Caleidoscópio e Direção-Geral do Património Cultural. 407 páginas, ISBN: 978-989-658-391-0.

Vejo o museu como um lugar de reflexão e de encontro connosco próprios e com o mundo (p.

\section{Da educação à criatividade}

1 A publicação Criatividade nos Museus, Espaços "Entre" e Elementos de Mediação (2016) resulta da investigação de doutoramento de Inês Ferreira (sob orientação de Alice Semedo e de Elisa Nascimento), que se caracteriza, antes de mais, por um generoso e exigente tratamento, sistematização e recolha de informação junto de um vasto conjunto de autores contemporâneos, desenvolvendo uma verdadeira taxonomia da criatividade, que será posteriormente submetida à validação teórica e prática junto dos profissionais dos museus e seus públicos. Nesse sentido, constitui uma síntese instrumental sobre a problemática que levanta, discorre e a que responde: como poderá o público ser chamado a participar na produção criativa do conhecimento a partir do museu?

2 O tema da criatividade, tantas vezes ambíguo, é aqui tratado de forma científica e experimental, sob o prisma da mediação. As operações de criatividade estão reféns dos 
elementos de mediação, ou melhor, dos elementos de mediação para a relação que ligará o público ao objeto museológico.

3 Na observação da investigação produzida em Portugal ao longo dos últimos 25 anos, assiste-se ao progresso da ideia de criatividade aplicada primeiro à educação e posteriormente à gestão e liderança da própria inovação, passando pelo estudo do pensamento artístico, da inteligência artificial e da inteligência emocional aplicadas a diversos contextos sociais, ou recorrendo a diferentes mediações técnicas. No estudo da criatividade aplicada à Museologia, a autora identifica o impacto da realidade aumentada (p. 25) ou da participação colaborativa na definição de inventários mais criativos (p. 140), reconhecendo na criatividade não só um meio para a inscrição de públicos, mas a condição transversal para a produção do conhecimento crítico.

O estudo concluirá da necessidade de abrangência da criatividade à dimensão da sociedade. Por isso os resultados têm um caráter pragmático e instrumental, aptos à instalação da revolução museológica para a criatividade, acreditando (com isso) estar a «ajudar a transformar o mundo e a sociedade» (p. 28). De espaços participativos (Simon 2010 apud Ferreira 2016, 9) e colaborativos (Brummett 2012 apud Ferreira 2016, 9), os museus ambicionam a construção de conhecimento, através de elementos mediadores (Svabo 2010 apud Ferreira 2016, 116), espoletando as capacidades críticas e criativas do visitante, tornando-o intérprete e performer de práticas de construção de significados (HooperGreenhill 2007 apud Ferreira 2016, 9).

5 Assim, os museus terão de "deixar de ser fornecedores de informação», para se tornarem «ferramentas para os visitantes poderem explorar as suas próprias ideias e chegar às suas próprias conclusões» (Freedman 2000 apud Ferreira 2016, 140). Para tornar o visitante construtor de significados, o museu terá de ser criativo e, por isso, em vez de concluir, o museu terá de questionar, ou melhor terá que ajudar o visitante a questionar, questionando-se.

6 O objetivo da criatividade imporá novas formas de mediação museológica, isto é, novas formas museográficas, introduzindo elementos de mediação para a criatividade. Os elementos de mediação de que nos fala a autora, constituirão a forma da sua própria museografia. Inês Ferreira defende a tese de que há espaço para a criatividade no espaço de mediação entre o visitante e a exposição, antecipando a relevância de contribuição do projeto museológico que passará, sem dúvida, pelo desenho da sua museografia.

7 A criatividade é neste livro tratada como uma relação, um modo de relação e não como um resultado. Trata-se, pois, de transformar o visitante de observador passivo em agente interpretativo e produtivo de conhecimento novo e próprio. Ainda que os resultados dessa capacidade criativa possam depender em parte, tanto da natureza do conhecimento, como da educação e preparação do visitante, questionamo-nos se a conceção geral do museu, a sua estrutura argumentativa, enfim a sua ideia enquanto mediador, não poderá ter um papel determinante no envolvimento do visitante para pensar com o museu e para além dele.

8 Á questão central da sua tese - Poderão os elementos de mediação promover a criatividade entre visitante e objeto? - Inês Ferreira conclui, propondo o papel da criatividade no séc. XXI, como contraponto à educação a que aspiravam os museus no séc. $\mathrm{XX}$, assumindo um papel de questionamento mais produtivo. $O$ cruzamento entre criatividade e educação; a materialização da criatividade (no) percurso já trilhado da educação, constituirá o principal contributo de inovação desta tese. Assim, a criatividade no séc. 
XXI como a educação no séc. XX, deverá contaminar todas as áreas do museu, passando as suas exposições a serem entendidas não só como espaços destinados à aprendizagem (pela educação), como também espaços de envolvimento produtivo (da criatividade). A criatividade levará mais longe as preocupações da educação, passando da eficiência comunicativa à superação, estímulo, curiosidade e questionamento do visitante, fazendo dele um agente ativo, intérprete e produtor cultural e não apenas um recetor de ideias alheias.

dologicamente, a autora recorre a uma abordagem fenomenológica (sobre a essência da experiência museal), fazendo a triangulação entre o conhecimento científico disponível (revisão da literatura) e o depoimento tanto dos técnicos dos museus como dos seus visitantes, mas interpretada a partir da sua própria experiência pessoal, o que resulta num processo de conhecimento não só pertinente e consistente, como muito realista.

10 Nas considerações finais, sintetizando os objetivos da construção de conhecimento e significado pelo visitante de museu, a autora reconhece o impacto que poderá ter o cruzamento da cultura educativa, com a cultura criativa que agora se propõe, abrindo novos desafios ao encontro de uma experiência mais polissémica, interdisciplinar, holística, democrática, comunicativa e subjetiva.

\section{Relevância e valor da mediação}

11 Partindo do reconhecimento do impacto da criatividade na sociedade, desafio que envolve desde os cidadãos às instituições, com o objetivo de promover criticamente a mudança - condição necessária à sobrevivência e realização humana pela adaptação ao novo -, Inês Ferreira propõe a sua declinação para os museus, apoiando-se no pensamento de vários autores. 0 desenvolvimento de um pensamento criativo nos museus (Gartenhaus 1997 apud Ferreira 2016, 48) é potenciador da imaginação (Bedford 2004 apud Ferreira 2016, 8) e meio de questionamento crítico pelos públicos (Bartels, Semper e Bevan 2010 apud Ferreira 2016, 8). Por isso, um museu criativo, (como lhe chama), é melhor que um museu não criativo. Nesse sentido, os museus têm, de forma criativa e colaborativa, integrado o visitante na construção de exposições, programas, projetos em coautoria (p. 367), (criando) «espaços laboratoriais onde os públicos possam experimentar o trabalho em progresso ou formas experimentais de pensar o que o museu possa ser» (Norris e Tisdale 2014 apud Ferreira 2016, 367).

Unidos pela indefinição de fronteiras e interceção de espaços, os museus criativos (categorizados pela autora como híbridos, líquidos, rizomáticos, laboratoriais e de polinização cruzada), exploram o espaço entre, como «um espaço de enorme potencial para aplicar estratégias e questionamentos que potenciem a criatividade» (p. 351).

Nesse sentido, a "mediação" é reconhecida como estímulo de provocação no espaço da relação entre visitante e o objeto exposto, propondo a sua interceção, oferecendo ao visitante as ferramentas para personalizar a sua visita em regime de self-service (p. 351). Esta «mediação não é simples intermediação mas transformação. [...] Mediar é ligar as partes para construir significados [...]» (p. 315); a ideia vem apoiada no argumento sobre os "modos de visita mediados" que acontecem sempre que, entre o objeto e o visitante, se coloca um elemento de relação que os liga (Svabo 2010 apud Ferreira 2016, 177). A ligação mediadora recorrerá a uma grande variedade de suportes: textuais 
(textos e folhas de sala, áudio-guias, tabelas interativas e roteiros; visuais (desenhos, gráficos, mapas, fotos e vídeos); artísticos (instalação artística da exposição, conto literário, obra musical e curadoria); de expressão (diários, áreas de posting, câmaras fotográficas, canto de atividades); e mistos (aqueles que recorram à palavra e à imagem, mesas interativas e instalações multimédia).

15 A complexidade da mediação museal ambiciona o nível da experiência imersiva (Dufrèsne-Tassé 2014, apud Ferreira 2016, 288), implicando a conjugação das funções cognitiva (identificar), imaginativa (reproduzir ou construir imagens) e afetiva (exprimir afinidades). A imersão assim entendida, não é, não pode ser, a experiência de perda da consciência de si, pelo envolvimento lúdico e alienante da simulação tecnicamente assistida, mas a convergência sobre o fluxo da experiência do conhecimento.

16 Ao considerar o museu (ele próprio) como instrumento de mediação, estamos naturalmente a valorizar a sua dimensão comunicativa e interpretativa e a desvalorizar a sua função contentora e protetora, enfatizando a sua função curatorial contra a sua função conservadora. Ora, como parece evidenciar o seu estudo, a criatividade nos museus dependerá mais dos elementos de mediação do que dos objetos expostos, cada vez mais dessacralizados e reduzidos a uma função documental. Do mesmo modo, a conceção museográfica que transparece da tese e apesar da advertência referida no livro, "quando um museu se centra em "explicar", carregar o visitante com "informação em torno do artefacto" - ensina um processo de receção passiva e não de observação ativa» (Rice e Yenawine 2002 apud Ferreira 2016, 155), a autora parece querer descurar a relevância do impacto da forma e de toda a estética de receção no condicionamento da leitura e interesse gerado pela peça musealizada. De facto, se o texto cuidadosamente redigido e fixado na parede da sala não conseguir persuadir à sua leitura, a sua presença será inútil e então sim, meramente decorativa.

Naturalmente que estes aspetos levantarão questões processuais na negociação entre a Museologia e a museografia, ou entre a relevância atribuída a proteger ou a comunicar o objeto. Como a autora confessa, uma das tensões (que decorre da existência destes elementos de mediação) é se, de facto, se podem tornar um fim (em si mesmos) e não um meio (p. 170).

18 Finalmente, o entendimento do museu como recurso criativo para a sociedade, porque «atiçam a imaginação [...] por causa das muitas histórias que contam» (Gartenhaus 1997 apud Ferreira 2016, 371) e «a própria sobrevivência humana depende do desenvolvimento dessas capacidades» (Daley 2005 apud Ferreira 2016, 371), implica a sustentabilidade dos museus (que por sua vez) dependerá da criatividade ao serviço da sua comunicação e missão. Portanto, a criatividade é hoje reconhecida como condição de sobrevivência para a perpetuação da instituição museal. Sem criatividade não haverá experiência interpretativa e sem experiência interpretativa não haverá visitantes interessados; ora, sem visitantes deixará de haver museus. Por isso, a criatividade inscrita na experiência museográfica será vital para o futuro da Museologia e esta obra um relevante instrumento para continuar a repensar o museu. Mas o que são elementos criativos de mediação museal se não o design da museografia? 


\section{BIBLIOGRAFIA}

Ferreira, Inês. 2016. Criatividade nos Museus: Espaços "Entre" e Elementos de Mediação. Vol. 3. Coleção Estudos de Museu. Casal de Cambra: Caleidoscópio e Direção-Geral do Património Cultural.

\section{AUTORES}

FRANCISCO PROVIDÊNCIA

Providência Design, Portugal, correio@fprovidencia.com 